\title{
Effects of loading rate on strength and deformation characteristics of gypsum mixed sand
}

\author{
Zain Maqsood ${ }^{1, *}$, Junichi Koseki ${ }^{1}$, and Hiroyuki Kyokawa ${ }^{1}$ \\ ${ }^{1}$ The University of Tokyo, Department of Civil Engineering, 113-8654 Tokyo, Japan
}

\begin{abstract}
It has been unanimously acknowledged that the strength and deformation characteristics of bounded geomaterials, viz. cemented soils and natural rocks, are predominantly governed by the rate of loading/deformation. Rational evaluation of these time-dependent characteristics due to viscosity and ageing are vital for the reliable constitutive modelling. In order to study the effects of ageing and loading/strain rate (viscosity) on the behaviour of bounded geomaterials, a number of unconfined monotonic loading tests were performed on Gypsum Mixed Sand (GMS) specimens at a wide range of axial strain rates; ranging from $1.9 \mathrm{E}-05$ to $5.3 \mathrm{E}+00 \% / \mathrm{min}(27,000$ folds), and at different curing periods. The results indicate shifts in the viscous behaviour of GMS at critical strain rates of $2.0 \mathrm{E}-03$ and $5.0 \mathrm{E}-01 \% / \mathrm{min}$. In the light of this finding, the results are categorized into three discrete zones of strain rates, and the behaviour of GMS in each of these zones is discussed. A significant dependency of peak strength and stress-strain responses on strain rate was witnessed for specimens subjected to strain rates lesser than $2.0 \mathrm{E}-03 \% / \mathrm{min}$, and the effects of viscosity/strain rate was found to be insignificant at strain rate higher than $5.0 \mathrm{E}-01 \% / \mathrm{min}$.
\end{abstract}

\section{Introduction}

Japan annually produces approximately 1.6 million tons of gypsum plasterboard waste during manufacturing, construction and demolishing stages of these plasterboards. In addition to the high disposal cost, the release of toxic hydrogen sulphide gas by the plasterboard waste sites under certain conditions also poses copious environmental hazards. In order to reduce the large quantities of this undesirable plasterboard waste, the process of recycling is often adopted to produce recycled gypsum. Recently, the use of this recycled gypsum for ground improvement is gaining attention in Japan, and the details of chemical and strength characteristics of recycled gypsum stabilized soils are also reported [1]. However, little effort has been made to comprehensively study the time-dependent strength and deformation behaviour of gypsum-treated geomaterials.

It is conspicuous that the strength and deformation characteristics of bounded geomaterials, viz. cemented soils and natural rocks, are prone to discernible changes with time, and such time-dependent variations are generally referred to as "time effects". Based on physical mechanisms, they are categorized into ageing effects and loading rate effects (or viscous effects) [2]. Thus, the crux of reliable constitutive modelling of bounded geomaterials is principally based on the rational evaluation of these time effects. In addition, the prediction of long-term performance of massive foundations and risk assessment of natural slopes also necessitate the novel cognizance of time-dependent strength and deformation characteristics.

In the recent decades, numerous prolific attempts have been made to comprehend the salient aspects of ageing and viscous effects. For instance, the findings of drained triaxial tests performed on cement-mixed gravelly soil indicated significant increase in strength and pre-peak stiffness with the increase of curing/ageing period. Additionally, the instantaneous stiffness in the pre-peak regions was reportedly increased with the corresponding increase in the instantaneous loading rate, and vice-versa. Such a viscosity type is termed as Isotach. Moreover, noticeable effects of complex interaction of ageing and viscosity on the strength and deformation characteristics were also witnessed [3].

Isotach viscosity in the pre-peak regions was also observed for undisturbed specimens of silt-sandstone and mudstone (of Kazusa formation, Japan) during consolidated triaxial creep tests [4]. Substantial increase in peak strength and elastic modulus due to viscous effects has been found for Maha Srakham Salt (of Maha Sarakham formation, Thailand), tested under unconfined and confined monotonic loading conditions [5]. Similar effects of viscosity have also been reported for Limestone (of Solnhofen Limestone formation, Germany) [6]. It is also noteworthy that the Isotach viscosity changes to a different viscosity type, known as TESRA, in the postpeak regions possibly due to the loss of bonding in the shear band [7]. Different types of viscosity and their characteristics have been thoroughly investigated [8].

On the other hand, the existence of critical values of strain rates has also been observed for mudstone (of Silurian formation, Australia, [9]) and Shale (of Kimmeridge Clay formation, England, [10]). The viscous behaviour of these rocks varies across these critical strain rates, and phenomenon of dilatancy hardening is presumed to be responsible for these discrepancies [11].

\footnotetext{
* Corresponding author: zain.nust@gmail.com
} 
Most of the above referred findings are based on a limited range of strain rate variations, and no efforts have been made to examine the effects of viscosity at strain rates lesser than $1.0 \mathrm{E}-04 \%$ per minute. Moreover, the effects of viscosity were typically studied without incorporating the influence of ageing, except for cementtreated soils. In the light of these aspects, the timedependent behaviour of gypsum-treated geomaterials demands thorough investigation at a relatively wider range of strain rates.

In the present study, a number of unconfined monotonic tests were performed on laboratory produced Gypsum Mixed Sand (GMS) specimens. A wide range of axial strain rates, ranging from $1.9 \mathrm{E}-05$ to $5.3 \mathrm{E}+00 \% / \mathrm{min}$ (27,000 folds), was opted, and a criterion to assess the reliability of test results has been discussed. In an effort to highlight the effects of ageing, GMS specimens cured for 3 days to 9 months were tested under unconfined monotonic loading condition at an average strain rate of $6.9 \mathrm{E}-02 \% / \mathrm{min}$.

Afterwards, the viscous behaviour of GMS was inspected at two different curing/ageing periods, viz. $3 \pm 0.5$ days and $90 \pm 3$ days ( 3 months), by performing unconfined monotonic tests at above stated wide range of axial strain rates. Finally the relationship between normalized strength and failure strain rate has been presented, and the results are categorized into three discrete zones of strain rates. The strength and deformation characteristics of GMS in each of these zones are discussed.

\section{Materials and testing procedure}

Fixed percentages by weight of Silica Sand No. 6 $(42.4 \%)$, gypsum $(33.9 \%)$ and water $(23.7 \%)$ were mixed uniformly, and the slurry was poured into air-tight plastic molds (diameter $=50 \mathrm{~mm}$, height $=100 \mathrm{~mm}$ ) for the preparation of GMS specimens. In order to meet the demands of extensive experimental work spanning over four years, two different batches (Batch A \& D) of same type of commercially produced gypsum were used in the present study.

All of the specimens were initially cured within the molds for $48 \pm 3$ hours to ensure the completion of hydration process. Afterwards, the specimens were demolded, and were wrapped in plastic sheets for further curing. The start of mixing process was considered as a reference point to calculate the total curing/ageing period.

Before testing, the cured specimens were wrapped with a rubber membrane to minimalize the detrimental variation of moisture content, especially during slow loading rate tests. To avoid tensile cracking of top and bottom ends of the specimens, dental gypsum was used for capping purposes. The details of these aspects are discussed elsewhere [12]. In addition to the conventional External Displacement Transducer (EDT), a pair of Local Displacement Transducers (LDT) was also attached at the opposite sides of specimen, as shown in Figure 1, to measure the local axial strains free from the unsolicited influence of bedding error [13].

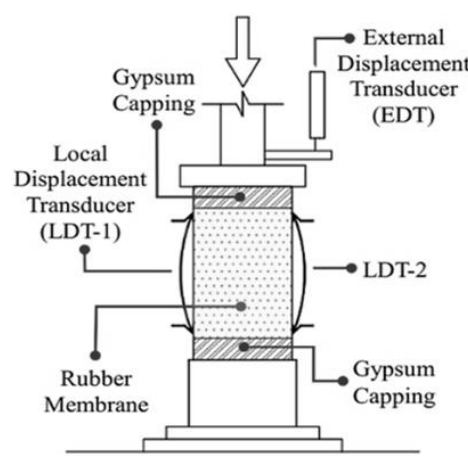

Fig. 1. Schematic illustration of GMS specimen

All of the tests on specimens prepared using Batch-A gypsum were performed using a strain-controlled apparatus. A moveable top cap was purposely used in this apparatus to eradicate any likely damage to the loading shafts, and the bottom pedestal was kept fixed during testing. Contrarily, another apparatus was also used to perform most of the tests on specimen prepared by BatchD gypsum having a moveable bottom pedestal with a fixed top cap.

\section{Reliability assessment criterion using local strain measurements}

Figure 2 shows the stress-strain relationships of two unconfined tests performed on specimens prepared using Batch-A gypsum. The curing periods of both of these specimens were $3 \pm 0.5$ days, and were tested at an average strain rate of $2.4 \mathrm{E}-02 \%$ per minute. In spite of all the efforts and precautions, considerable undesirable variations in peak strength values of GMS specimens were observed under similar testing conditions, as evident from Figure 2. For instance, the peak strength value of specimen S150 is $30 \%$ higher than that of S153, and such disparities pose an immense challenge for the investigation of time-dependent behaviour as the effects of viscosity on strength values are typically smaller than these inherent variations.

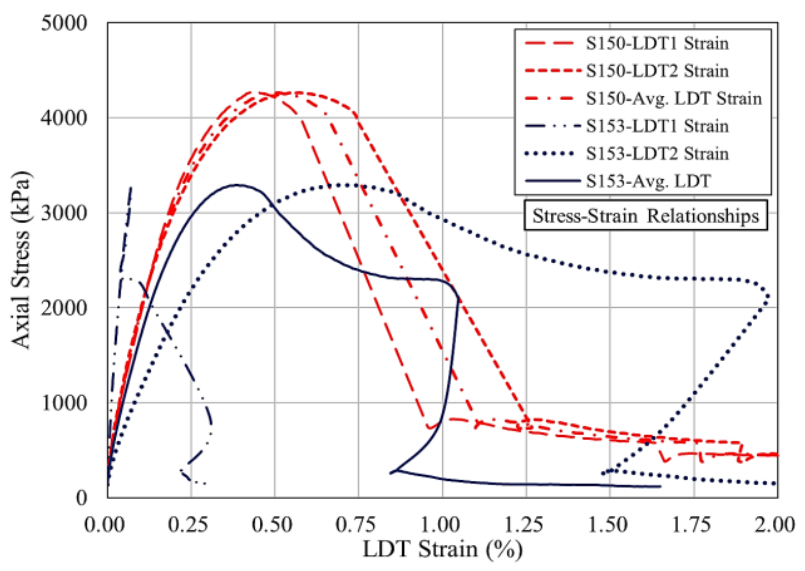

Fig. 2. Typical stress-strain relationships (average strain rate $=$ $2.4 \mathrm{E}-02 \% / \mathrm{min}$., curing period $=3 \pm 0.5$ days, Batch-A) (modified from [14]) 
A methodology based on the quantitative analysis of the discrepancies of local strains measured at the opposite sides of specimens was proposed to overcome the above highlighted issue. For the case of S153, the local strains measured by the two LDTs are noticeably different with each other in pre-peak and near-peak regions, indicating an uneven distribution of axial strains along the sides of specimen, as shown in Figure 2. Based on this observation, it was conceived that such uneven strains could be responsible for the reduction in peak strength. Conversely, the local strains measured at opposite sides of specimen S150 are relatively alike, resulting into a higher strength value. In order to quantify these discrepancies in locally measured strains, Absolute Average Difference (AAD) of these strains was computed at different strain levels using the following equation:

$$
A A D=\left|\left(\varepsilon_{L D T 1}-\varepsilon_{L D T 2}\right) /\left(\varepsilon_{L D T 1}+\varepsilon_{L D T 2}\right)\right| * 100
$$

where $\varepsilon_{L D T 1}$ and $\varepsilon_{L D T 2}$ are the strains measured by LDT1 and LDT2 respectively, as illustrated in Figure 1.

Figure 3 shows the relationship between Unconfined Compressive Strength (UCS) values and AAD computed at $50 \%$ of failure strain, measured by EDT, of $3 \pm 0.5$ days cured specimens (Batch-A) tested at five different loading rates ranging from $1.6 \mathrm{E}-01$ to $3.0 \mathrm{E}$ $03 \% / \mathrm{min}$. It is obvious from Figure 3 that the strength values of specimens tested at higher strain rates are significantly higher due to the viscous behavior of GMS, and these details will be discussed in the upcoming sections.

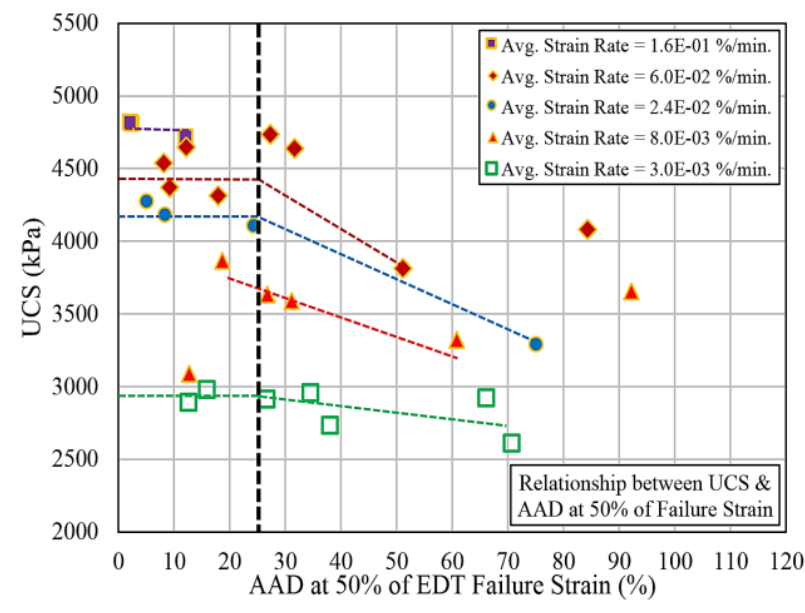

Fig. 3. Relationships between UCS and AAD at $50 \%$ of EDT failure strain (curing period $=3 \pm 0.5$ days, Batch-A) (modified from [14])

At a particular strain rate, the strength values generally decrease with the increase in AAD of locally measured strains for specimens tested, as evident in Figure 3. Similar dependency of strength values of GMS specimens on AAD of local strains was witnessed at other failure strain level. Furthermore, it was also observed that the value of AAD of local strains usually reduces with the increase of strain level, and further details of this methodology are discussed elsewhere [14].

Based on this approach, test results having ADD values lesser than $25 \%$ at $50 \%$ of failure strain levels were only selected for the further analysis of time-dependent behavior of GMS. A total of 55 unconfined monotonic tests were conducted for the present study, and 20 test results were rejected based on this criterion; indicating a rejection rate of approximately $35 \%$.

It is noteworthy that this criterion has been strictly adopted for all the monotonic test results presented in this manuscript. Moreover, the variations in the strength values of the selected test results based on this criterion were presumed to be satisfactory, as evident from Figure 3 , and this aspect will be further discussed in the next section.

\section{Ageing effects}

To examine the effects of ageing/curing on the strength and deformation characteristics of GMS, a total of 23 unconfined compression tests were performed on specimens (Batch-A) aged/cured for time ranging from 3 \pm 0.5 days to $270 \pm 3$ days ( 9 months). The average strain rate of $6.6 \mathrm{E}-02 \% / \mathrm{min}$ was opted for these tests, and a plot between UCS and ageing/curing period is presented in Figure 4.

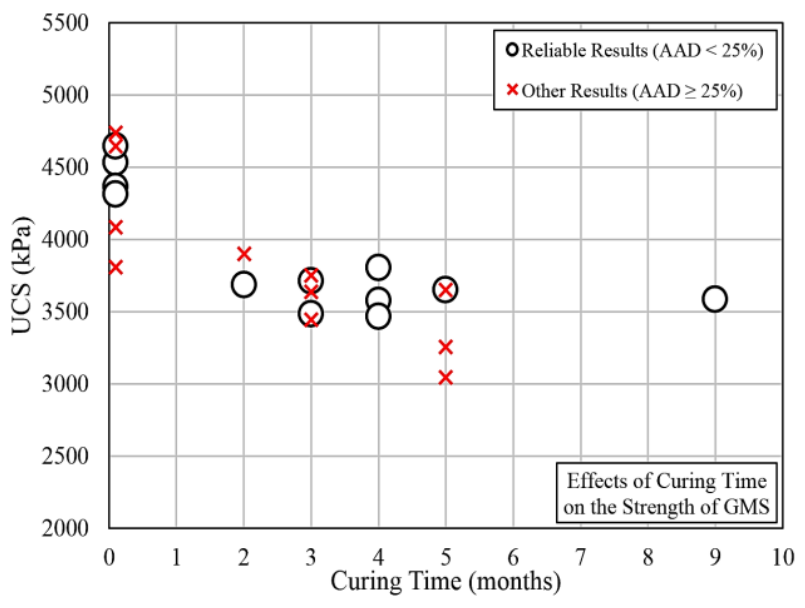

Fig. 4. Relationships between UCS and ageing/curing period (average strain rate $=6.6 \mathrm{E}-02 \% / \mathrm{min}$., Batch-A)

A substantial reduction in the peak strength was observed in the initial two months of curing, but these effects of ageing become virtually insignificant after two months, as evident in Figure 4. Additionally, irrefragable variations in the strength values under similar testing conditions can also be witnessed in Figure 4, particularly at curing periods of $3 \pm 0.5$ days and 5 months.

Nevertheless, the results selected based on the criterion of AAD of local strains show a higher degree of repeatability. For instance, the standard deviation of all the strength values at a curing period of $3 \pm 0.5$ days is 318 $\mathrm{kPa}$, whereas this reduces to only $154 \mathrm{kPa}$ for the selected results at this curing period. Based on the reliable results, it is established far beyond any doubt that the effects of ageing on the peak strength of GMS can be practically ignored for a curing range of 2 to 9 months.

In order to study the effects of the possible interaction of ageing and strain rate (viscosity) effects on the behaviour of GMS, two curing periods of $3 \pm 0.5$ days and 
$90 \pm 3$ days ( 3 months) were selected. The peak strength and failure strain values at a strain rate of $2.0 \mathrm{E}-02 \% / \mathrm{min}$ are presented in Table 1. Further details of this phenomenon will be discussed in the next section.

Table 1. UCS and locally measured failure strain of GMS at an average strain rate of $2.0 \mathrm{E}-02 \% / \mathrm{min}$.

\begin{tabular}{|c|c|c|c|}
\hline \multirow{2}{*}{$\begin{array}{c}\text { Gypsum } \\
\text { Batch }\end{array}$} & $\begin{array}{c}\text { Curing } \\
\text { Time }\end{array}$ & UCS & $\begin{array}{c}\text { LDT Failure } \\
\text { Strain }\end{array}$ \\
\cline { 2 - 4 } & (days) & $\mathbf{( k P a )}$ & $\mathbf{( \% )}$ \\
\hline \multirow{2}{*}{$\mathrm{A}$} & $3 \pm 0.5$ days & 4100 & 0.485 \\
\cline { 2 - 4 } & $90 \pm 3$ days & 3200 & 0.465 \\
\hline \multirow{2}{*}{$\mathrm{D}$} & $3 \pm 0.5$ days & 3465 & 0.431 \\
\cline { 2 - 4 } & $90 \pm 3$ days & 2515 & 0.440 \\
\hline
\end{tabular}

The typical stress-strain relationships of specimens cured up to 9 months are presented in Figure 5. Even at the same strain rate, a stiffer response was observed for specimen cured only for $3 \pm 0.5$ days, and the stiffness of GMS decrease markedly during the initial two months of curing, as shown in Figure 5. It is also observable from Figure 5 that the specimen cured for 2 months shows unexpected ductile behaviour, and the stiffness decreases gradually during curing period of 3 to 9 months. Moreover, a clear and distinct shear band formation was witnessed for all the specimens tested at different curing periods.

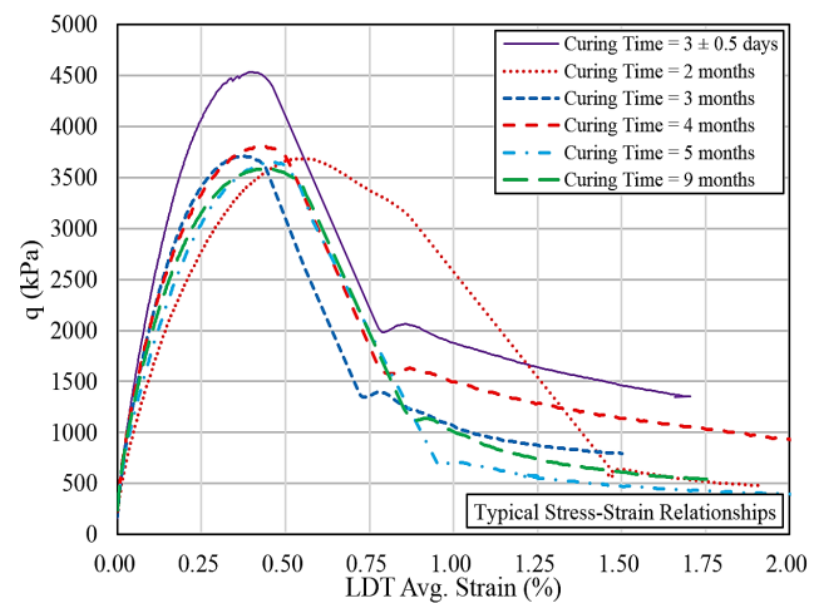

Fig. 5. Typical stress-strain relationships (average strain rate $=6.6 \mathrm{E}-02 \% / \mathrm{min}$, Batch-A)

\section{Strain rate effects (viscous effects)}

The stress-strain relationships of GMS specimens (BatchD) cured for $90 \pm 3$ days ( 3 months) are plotted in Figure 6. As anticipated, the Isotach viscosity of GMS is undeniably identifiable from these stress-strain relationships. The peak strength and stiffness reduce with the decrease in strain rate, and this tendency is pronounced significantly for specimens tested at strain rates lesser than 2.4E-02\%/min., as shown in Figure 6.

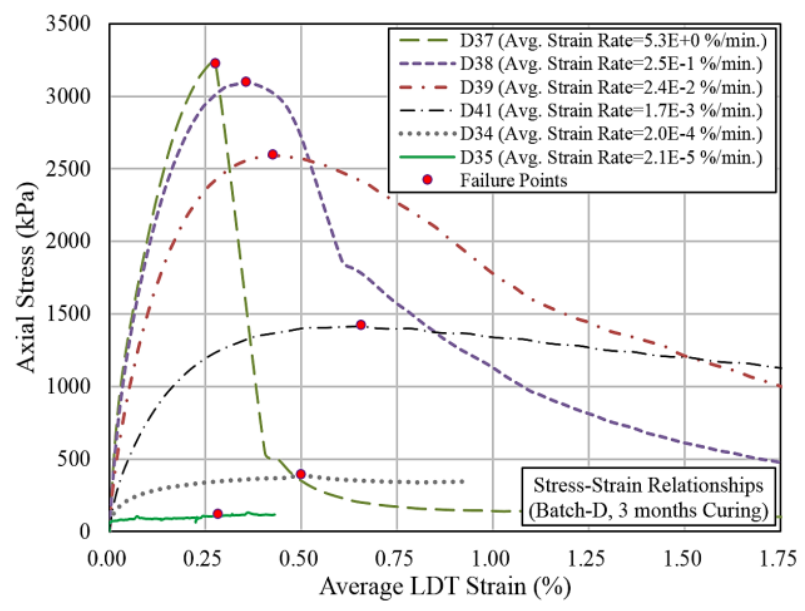

Fig. 6. Stress-strain relationships (curing period $=90 \pm 3$ days, Batch-D)

It is noteworthy that the peak strength value of specimen D37 tested at the highest strain rate of $5.3 \mathrm{E}+00 \% / \mathrm{min}$ is $3327 \mathrm{kPa}$, and the strength value dropped incalculably to merely $121 \mathrm{kPa}$ for specimen D35 tested at the slowest strain rate, viz. $2.1 \mathrm{E}-05 \% / \mathrm{min}$. Therefore, a peak strength reduction up to about $96 \%$ can be witnessed for GMS (Batch-D) due to the decrease in strain rate by 252,000 times, as evident in Figure 6 . In addition, strain softening in the post-peak region is fairly noticeable at higher strain rates, whereas this phenomenon diminishes gradually with the decrease in strain rates.

In an effort to fully comprehend the viscous behaviour of GMS, a full logarithmic plot between normalized peak stress and strain rate at failure for all the tests is presented in Figure 7. The normalized peak stress was calculated by dividing the failure stress value with the UCS obtained at a strain rate of $2.0 \mathrm{E}-02 \% / \mathrm{min}$, under other similar testing conditions. Except for a test performed at strain rates of $5.3 \mathrm{E}+00 \% / \mathrm{min}$, the failure strain rates were estimated by calculating the strain rate between $98 \%$ of failure strain and failure strain. Owing to the technical constrains of data storing system, the strain rate between approximately $90 \%$ of failure strain and failure strain was used to compute the failure strain rates for the test conducted at $5.3 \mathrm{E}+00 \% / \mathrm{min}$. 


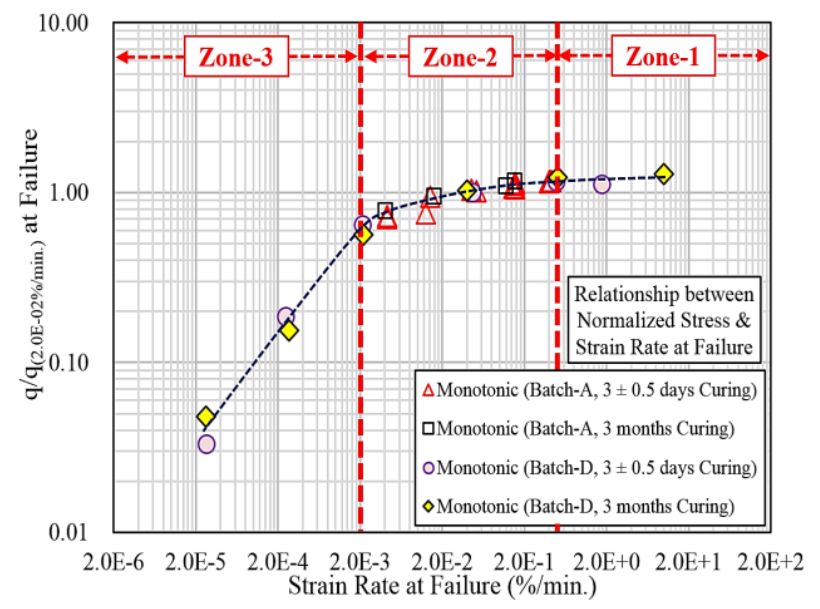

Fig. 7. Relationship between normalized failure stress and strain rate at failure

In spite of the effects of ageing/curing period on the peak strength of GMS, the effects of viscosity/strain rate on the normalized strength are of similar magnitude for both $3 \pm 0.5$ days and $90 \pm 3$ days ( 3 months), as evident from Figure 7. Therefore, these results assure that the phenomenon of interaction between ageing and viscosity effects is not discernible for GMS. Furthermore, the effects of viscosity are also alike for specimens prepared by Batch-A and Batch-D gypsum.

Figure 8 shows a full logarithmic plot between normalized failure strain and strain rate at failure. The normalized failure strain rates were computed by dividing the failure strain values with the failure strain rate of specimens tested at $2.0 \mathrm{E}-02 \% / \mathrm{min}$, under other similar tested conditions. The existence of same critical strain rates are also evident in Figure 8, and the plot has been divided into similar three zones of strain rates. The effect of viscosity/strain rate on the failure strain of specimen tested at strain rates higher than $5.0 \mathrm{E}-01 \% / \mathrm{min}$, viz. Zone1 , is almost insignificant.

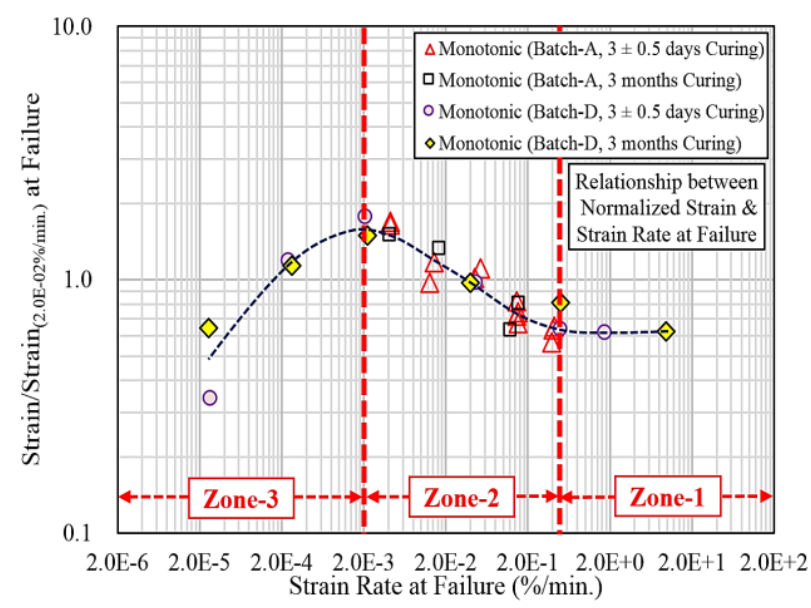

Fig. 8. Relationship between normalized failure strain and strain rate at failure

The maximum values of failure strains were witnessed at a strain rate of $2.0 \mathrm{E}-03 \% / \mathrm{min}$, and these values decrease with the further increase in strain rate up to $5.0 \mathrm{E}$ $01 \% / \mathrm{min}$. Conversely, a decreasing trend in the values of failure strain with the decrease in strain rate can be found for specimens tested at strain rate lesser than 2.0E03\%/min, viz. Zone-3.

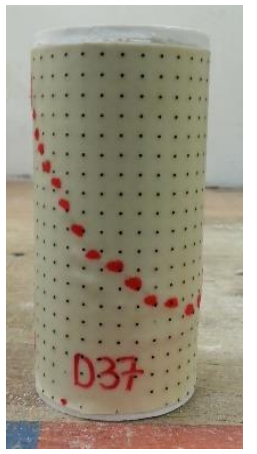

(a)

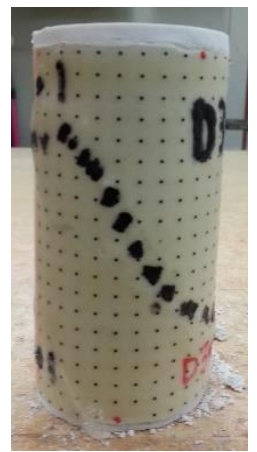

(b)

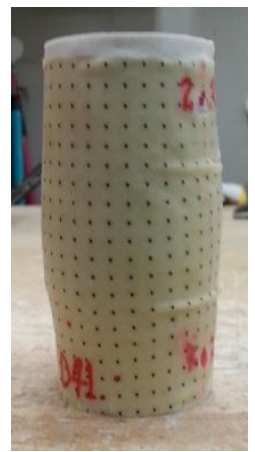

(c)
Fig. 9. Shear band formation: a) D37 (5.3E+00\%/min), b) D39 $(2.4 \mathrm{E}-02 \% / \mathrm{min})$ and $\mathrm{D} 41(1.7 \mathrm{E}-03 \% / \mathrm{min})$

The strain localization characteristics of GMS specimens were also affected by the strain rates. At loading rates higher than $2.0 \mathrm{E}-03 \% / \mathrm{min}$, viz. Zones 1 and 2 , visible formation of shear bands was observed, as shown in Figure 9(a) and 9(b). However, for all the specimens tested at a strain rate lesser than 2.0E$03 \% / \mathrm{min}$, viz. Zone-3, only bulging was observed and no visible cracks or shear bands at residual stress levels, as shown in Figure 9(c).

\section{Conclusions}

The effects of aging/curing and viscosity/loading rate on the strength and deformation characteristics of GMS were studied by conducting unconfined monotonic tests at a wide range of axial strain rates, ranging from 1.9E-05 to $5.3 \mathrm{E}+00 \% / \mathrm{min} \quad(27,000$ folds $)$, and at different ageing/curing periods. A criterion based on the local strain measurements was proposed, and the results were scrutinized to overcome the undesirable variations in peak strength values.

The effects of ageing/curing period on peak strength was found to be momentous only during the initial two months of curing, and peak strength values were found to be independent after this period of curing. An abrupt change in the viscous behaviour of GMS was found at two critical strain rates, viz. 2.0E-03 and 5.0E-01\%/min, and based on these critical strain rates the results were divided into three zones of strain rates.

The effects of viscosity/strain rate on peak strength were maximum for specimens tested at strain rates lesser than $2.0 \mathrm{E}-03 \% / \mathrm{min}$, viz. Zone-3, as normalized strength dropped more than $60 \%$ with only a 100 times reduction in strain rates in this zone. For strain rate higher than 5.0E$01 \% / \mathrm{min}$, viz. Zone- 1 , the peak strength and failure strain values were found to be almost independent of strain rates. Moreover, peak strength values of Zone-2 were affected by the change in strain rates, but this dependency was found to be relatively lesser than Zone-1. Furthermore, the interaction between ageing and viscosity was not observed for GMS. 
The failure strain values were also divided into these three zones of strain rates, and the maximum values of failure strain were reported at $2.0 \mathrm{E}-.03 \% / \mathrm{min}$. An opposite trend of dependency of failure strain on strain rate was observed in Zone-2 and Zone-3. Moreover, visible shear bands were observed for specimen tested at strain rates higher than $2.0 \mathrm{E}-03 \% / \mathrm{min}$, viz. Zone- 1 and Zone-2, and only bulging was witnessed for specimen tested at strain rates lesser this strain rate.

\section{References}

1. A. Ahmed, K. Ugai, T. Kamei, Soils Found, 51, 6, 975-990 (2011)

2. L. Kongsukprasert, R. Kuwano, F. Tatsuoka, The Thirty-seventh Japan National Conference on Geotechnical Engineering, 813-814 (2002)

3. L. Kongsukprasert, F. Tatsuoka, Soils Found, 45, 6, 55-74 (2002)

4. H. Kimitoshi, M. Matsumoto, F. Tatsuoka, J. Koseki, SOILS FOUND, 41, 2, 21-38 (2001)

5. K. Fuenkajorn, T. Sriapai, P. Samsri, Eng. Geol., 135-136, 10-23 (2012)

6. E.H. Rutter, Int. J. Rock Mech. Min. Sci. Geomech. Abstr., 9, 2, 183-189 (1972)

7. Y. Miyashita, J. Koseki, K. Namikawa, M. Matsumoto, 6th International Symposium on Deformation Characteristics of Geomaterials, 575582 (2015)

8. F. Tatsuoka, H. Di Benedetto, T. Enomoto, S. Kawabe, W. Kongkitkul, Soils Found, 48, 1, 41-60 (2008)

9. H. K. Chiu, I.W. Johnston, I.B. Donald, Int. J. Rock Mech. Min. Sci. Geomech. Abstr., 20, 3, 107-120 (1983)

10. G. Swan, J. Cook, S. Bruce, R. Meehan, Int. J. Rock Mech. Min. Sci. Geomech. Abstr., 26, 2, 135-149 (1989)

11. W.F. Brace, R.J. Martin, Int. J. Rock Mech. Min. Sci. Geomech. Abstr., 5, 415-426 (1968)

12. Z. Maqsood, J. Koseki, GeoKanto, Japanese Geotechnical Society, (2015)

13. S. Goto, F. Tatsuoka, S. Shinuya, Y. Kim, Soils Found, 31, 1, 169-180 (1991)

14. Z. Maqsood, J. Koseki, The 18th International Summer Symposium, JSCE, 69-70, (2016) 